\title{
A Snapshot of Social Risk Factors and Associations with Health Outcomes in a Community Sample of Middle Eastern and North African (MENA) People in the U.S.
}

\author{
Minal R. Patel ${ }^{1,2,4} \cdot$ Molly Green $^{1} \cdot$ Madiha Tariq $^{3} \cdot$ Asraa Alhawli $^{3} \cdot$ Nadia Syed $^{3} \cdot$ Paul J. Fleming $^{1} \cdot$ Ali Ali $^{2}$. \\ Elizabeth Bacon ${ }^{2} \cdot$ Stefanie Goodall ${ }^{2} \cdot$ Alyssa Smith ${ }^{1} \cdot$ Kenneth Resnicow $^{1,2}$
}

Accepted: 25 February 2021 / Published online: 11 March 2021

(c) The Author(s), under exclusive licence to Springer Science+Business Media, LLC, part of Springer Nature 2021

\begin{abstract}
Social factors (e.g. housing, food security, etc.) contribute significantly to health. The purpose of this study is to describe social risk and social exclusion factors in one of the largest Middle Eastern and North African (MENA) populations in the U.S. and their association with health outcomes. We conducted a cross-sectional study with a community convenience sample of 412 adults who self-identify as MENA. Weighted, adjusted linear regression models were used to examine relationships of interest. Prevalent social risks included transportation barriers to healthcare (33\%), food insecurity (33\%), and financial strain (25\%). In adjusted models, perception of being treated unfairly (Estimate (SE) $0.08(0.04), \mathrm{p}<0.05)$ and fear of deportation $(0.26(0.06), \mathrm{p}<0.001)$ were associated with more social risk factors. More social risk factors were associated with worse self-reported health $(0.09(0.03), \mathrm{p}<0.01)$, more chronic conditions $(0.11(0.03), \mathrm{p}<0.004)$, and more mental health symptoms $(0.34(0.14) \mathrm{p}<0.01)$.Social risk is high among those perceiving unfairness and fear deportation. Those with more social risk factors reported worse health. These findings have implications for social needs screening and referral models that can best serve U.S. MENA sub-populations.
\end{abstract}

Keywords Social risk factors $\cdot$ Social determinants of health $\cdot$ Middle Eastern North African $\cdot$ Health disparities $\cdot$ Health status $\cdot$ Immigrants

\section{Introduction}

The increased recognition of the social and behavioral determinants of health (e.g. the conditions in which people live, work and play) on health outcomes by private and public health insurance streams, policy makers, researchers, clinicians and health care delivery systems has led to a growing

Minal R. Patel

minalrp@umich.edu

1 Department of Health Behavior \& Health Education, University of Michigan, Ann Arbor, MI, USA

2 University of Michigan Rogel Cancer Center, Ann Arbor, USA

3 Arab Community Center for Economic and Social Service, Dearborn, MI, USA

4 Department of Health Behavior \& Health Education, University of Michigan School of Public Health, 1415 Washington Heights, Ann Arbor, MI 48109-2029, USA interest and investment in mitigating social risks, which are the manifestations of social determinants of health at the individual level (e.g. food insecurity, transportation barriers, unstable housing, etc.) [1]. More and more health care delivery settings and social service agencies are investing in social risk screening and linking to resources [2]. Multiple studies have identified social risk factors in various sub-populations to inform resource mobilization and tailored screening and referral models [3-6]. However, little work has been done to examine social risk factors in communities of Middle Eastern and North African (MENA) descent in the U.S., a population known to experience health inequities [7].

The lack of data on the social risk factors among MENA people living in the U.S. is in part due to the lack of an ethnic identifier in the U.S. Census and national health surveys [8]. The U.S. Census classifies MENA people as racially white, although people can identify themselves as MENA in subsequent open-ended items. People of MENA ethnic backgrounds in the U.S. comprise a fast-growing group. The MENA population is diverse, representing all $22 \mathrm{Arab}$ 
League nations, with the primary countries of origin being Lebanon, Egypt, Syria, Iraq, Yemen, and Palestine. There is also a high percentage of Iraqis in the U.S., many of whom are Christians of Chaldo-Assyrian descent [9-11].

Southeast Michigan is home to the second largest MENA population (around 211,000 by 2017 Census estimates) with California having the largest (around 307,000) [9]. In 2016, a state representative sample of Arabs and Chaldeans in Michigan showed that rates of fair/poor health status were similar to those seen in African American and Latino/Hispanic population, which is higher when compared to whites [12]. These data also showed high levels of two social risk factors within the MENA population: food insecurity and perceived financial strain. Data further reveal that the most important health challenges in the MENA population in Michigan are mental and behavioral health issues, including clinical depression (16\%) and self-report of fair or poor health (23\%) [12]. However, data were not available for a more comprehensive set of social risk factor domains endorsed by the National Academy of Medicine (NAM) for social risk screening, and the Healthy People 2020 'placebased' organizational framework for social determinants of health that also include more specific, individual-level domains related to healthcare access experiences and social disadvantage [13, 14].

A host of factors may influence the types of social risk factors seen in the MENA community, including social exclusion factors. For example, experiences of discrimination among the MENA community are well-documented, including post $9 / 11$ government surveillance and discrimination, and more recent anti-immigration rhetoric [15-18]. Discrimination impacts health by denying access to resources, dignity, and a high quality of life [19]. Few social risk screening tools have actually measured more in-depth experiences of discrimination beyond asking about racial/ ethnic identity. While racial/ethnic identity can be a proxy for disadvantage or discrimination within a racist U.S. sociopolitical environment, there are also more precise ways to measure experiences of discrimination and disadvantages [13]. One screening tool in the pediatric setting inquired about parental experiences with discrimination [20]; another study in the transgender population identified discrimination among one of several prevalent social risk factors [6]; and a recent study screened for immigration-related concerns in a Latinx undocumented population [3].

Gaps remain in understanding social risk factors of vulnerable MENA communities in the U.S and the types of screening and referral models that would have the most impact addressing these needs. These questions are important to address, given the large investments in both federal and state agencies, such as the Centers for Medicare \& Medicaid Services, in testing innovative models for screening and referral, and growing interest by private and public health insurance streams and healthcare delivery systems to incorporate these approaches into their practice to comprehensively meet the health needs of diverse patients.

The purpose of this study is to build on previous research and describe the prevalence of social risk factors in one of the largest MENA communities in the U.S., and their association with social exclusion factors and health outcomes.

\section{Methods}

\section{Data Source and Sample}

Data came from a cross-sectional survey exploring health behavior, health knowledge and attitudes, and social factors of a community convenience sample of adults 18 years of age and older and self-identifying as either Arab or Chaldean living in Southeast Michigan. All study procedures were reviewed and approved by our university's Institutional Review Board. A self-administered survey was distributed across 12 community settings (e.g. grocery stores, local eateries, clinics, mosques, churches, community-based organizations, and community events) in three counties between May and September 2019. Recruitment was completed through posters, fliers and in-person outreach. Participants were given the option of completing either a pen and paper or an online survey form, with assistance if needed from trained, bilingual interviewers. Surveys were available in English and Arabic, and participants were given a modest monetary incentive. This analysis includes 412 participants with completed surveys for analysis.

\section{Measures and Outcome Assessments}

\section{Social Risk Factors}

We first report the prevalence of social risk factors and then examine both predictors and consequences of these social risks. Social risks were used as both an independent predictor of health status and as an outcome for understanding demographic and social exclusion predictors. We focused on eight social risk factors: transportation barriers with healthcare, food insecurity, financial strain, unemployment, unstable housing, inadequate patient-centered care, lack of insurance, and reporting no usual source of care. Transportation barriers with healthcare was measured by asking participants how often transportation is a problem in getting health care (5-point Likert scale: Never-Always). A response of 'always', 'usually' and 'sometimes' was considered an 'unmet social need'. Food insecurity was measured by asking participants how often the following statement was true: 'The food I bought did not last and I did not have money to get more' (never, sometimes, often). 
A response of 'often' and 'sometimes' was considered an 'unmet social need'. Financial strain was measured by asking participants to select which statement comes closest to your own feelings about your household income these days (4-point Likert scale: living comfortably-finding it very difficult). A response of 'finding it difficult and 'finding it very difficult' was considered an 'unmet social need'. Unemployment was measured by asking about current occupational status. Unstable housing was measured by asking participants where they have lived the most during the past 2 months [21]. Any response other than apartment/house/ room with or without a government subsidy was considered an unmet social need. Inadequate patient-centered care was measured by asking participants how often during the past 12 months their primary care physician did the following: provide a chance to ask questions, give attention to feelings and emotion, involve you in decisions about your healthcare, understand actions to take care of health, explain things in a way you understand, spend enough time with you, and help you deal with feelings of uncertainty about your healthcare (4-point Likert scale: always-never) [22]. Consistent responses of 'never' across each indicator was considered an 'unmet need'. Participants were asked if they have any type of health coverage or a usual source of care $(\mathrm{Y} / \mathrm{N})$, with responses of 'no' indicating an unmet need. These binary indicators of unmet needs were summed to create a continuous variable (range 0-7) for multivariable regression analyses.

\section{Social Exclusion Factors}

We measured four social exclusion factors: perceived discrimination, perception of being treated unfairly, deportation worry, and government mistrust. To measure perceived discrimination, we used the 9-item Everyday Discrimination scale [23]. Respondents indicated how often they experience nine types of discrimination with six response options ranging from 'Never' to 'Almost Everyday'. We computed a mean across the 9 items, which resulted in a score range of 1-6. Scores were divided into tertiles (low, medium, high) [19], with 'medium' and 'high' scores considered an 'unmet social need'. Perception of being treated unfairly was assessed with a single-item from the Whitehall study [24, 25], which was worded as: "I often have the feeling that I am being treated unfairly" (6-point Likert scale: strongly disagree-strongly agree). Deportation worry was assessed by asking participants if they worry that a family member or someone they are close to will be deported (5-point Likert scale: not at all worried-extremely worried). Government mistrust was assessed with a single-item, "The U.S. government is trying to make things better for Arab Americans" (6-point Likert scale: strongly disagree-strongly agree), with lower scores indicating greater distrust.

\section{Health Outcomes}

Number of chronic conditions was assessed by asking if the respondent had ever been diagnosed with (1) cancer, (2) diabetes or high blood sugar, (3) high blood pressure or hypertension, (4) depression, or (5) heart condition such as heart attack, angina, or congestive heart failure $(\mathrm{Y} / \mathrm{N})$. Items were summed for regression analysis. Health status was assessed by the following survey item: "In general, would you say your health is... (Excellent, very good, good, fair, poor)?" Mental health symptoms were assessed with the four item PHQ-4 [26], which asked how often have you been bothered by any of the following problems: (1) little interest or pleasure in doing things, (2) feeling down, depressed, or hopeless, (3) feeling nervous, anxious, or on edge, and (4) not being able to stop or control worrying (4-point Likert scale: Not at all-Nearly every day). Higher scores indicated worse mental health. Alpha for the four items in our sample was 0.91 .

We measured demographic and identity-related characteristics such as educational attainment, household income, age, gender, ethnicity, country of birth (U.S. vs. not U.S.), length of time in the U.S., language spoken in the home, religion, and marital status using standard measures from established national surveys.

\section{Data Analysis}

All analyses were conducted using SAS 9.4 (Cary, NC). Analyses included survey weights to adjust for country of origin. Weighted descriptive statistics were computed to examine demographic, identity, social exclusion and health factors of the sample and prevalence of social risks. Bivariate analyses ( $t$ tests) examined differences in the mean number of social risk factors by demographic, identity, social exclusion and health factors.

Multivariable linear regression models were used to examine the associations between social exclusion and identity factors (perceived discrimination, perception of being treated unfairly, fear of deportation, Arab identity, length of stay in the U.S., and government mistrust) and number of social risk factors. Models were adjusted for age, gender, income, education, and U.S. birth. Similar models were also used to examine the association between number of social risk factors and indicators of health status (self-report health status, number of chronic conditions, and mental health symptoms). Alpha values less than 0.05 were considered significant. 


\section{Results}

\section{Participant Characteristics}

Table 1 shows weighted demographic, health, and social characteristics of participants. Mean age of participants was 38.4 years (95\% CI 35.1-41.7), and $61.2 \%$ was female. Fiftyone percent of participants report being married, $46 \%$ had an educational attainment of college graduate or above, and $70 \%$ report a household income $\leq \$ 50,000$. Ninety-percent reported Arab identity, $74 \%$ were Muslim, and 58\% were non-U.S. born. Among the non-U.S. born, 37\% reported being in the U.S. for 10 years or less.

Forty-seven percent report a chronic disease diagnosis, 50\% report very good/excellent health, and mean mental health symptoms was 6.63 (95\% CI 6.15-7.11) (range 1-16).

\section{Prevalence of Social Exclusion Risk Factors}

Table 1 also shows weighted prevalence of social exclusion risk factors. Sixty-percent of participants report perceived discrimination, 37\% report perception of being treated unfairly, $17 \%$ deportation worry, and $49 \%$ reported government mistrust.

\section{Prevalence of Social Risk Factors (Individual-Level Social Determinants of Health) and Differences by Demographic, Identity, Social Exclusion Factors and Health Outcomes}

Figure 1 shows the prevalence of social risk factors among participants. The most prevalent reported social risks were: transportation barriers to healthcare (33\%), food insecurity (33\%), financial strain (25\%), unemployment (17\%), and unstable housing (16\%). Thirty-three percent of participants report one social risk factor, $27 \%$ report 2, 20\% report 3 social risks, $7 \%$ report 4 and 5 social risks, and $3 \%$ reported none. More social risk factors were evident among those identifying as female $(\mathrm{p}<0.01)$, with education of some college or less $(\mathrm{p}<0.001)$, with lower income $(\mathrm{p}<0.001)$, Arab versus Chaldean descent $(\mathrm{p}<0.02)$, non-U.S. born $(\mathrm{p}<0.05)$, in the U.S. for fewer years $(p<0.003)$, originating from Egypt, Syria, Yemen versus other countries ( $\mathrm{p}<0.001)$, and who speak Arabic at home $(\mathrm{p}<0.01)$ (Table 1). More unmet needs were also evident among those reported being treated unfairly $(\mathrm{p}=0.03)$, worried about deportation $(\mathrm{p}<0.002)$, and those who reported worse health $(\mathrm{p}<0.01)$ (Table 1).
Associations Between Identity and Social Exclusion Factors and Number of Social Risk Factors

In models adjusted for age, gender, income, education, and U.S. birth, perception of being treated unfairly [Estimate (SE): 0.08 (0.04), p < 0.05], and fear of deportation [0.26 $(0.06), p<0.001]$, were associated with more social risk factors (Table 2).

\section{Associations Between Number of Social Risk Factors and Health Status}

In models adjusted for age, gender, income, education, and U.S. birth, more social risk factors was significantly associated with worse self-reported health [0.09 (0.03), $\mathrm{p}<0.01]$, more chronic conditions [0.11 (0.03), $\mathrm{p}<0.004]$, and more mental health symptoms $[0.34(0.14) \mathrm{p}<0.01]$ (Table 3$)$.

\section{Discussion}

This study is one of the first to document social risk factors-manifestations of social determinants of health-at the individual level, within a MENA community in the U.S. In this study, we found a high prevalence of social risks and the volume of unmet needs differed by demographic, identity, and social exclusion factors. We also found that having more social risks was associated with worse self-reported health, chronic disease and mental health symptoms. Our findings align with other work in immigrant and marginalized communities demonstrating high prevalence of social risk factors and unmet needs, the relationship between social risks and health, and the influence of sociocultural, economic, and political contextual factors in immigrant communities [3, $5,6,27,28]$.

Results document high prevalence and significant differences in social risks by identity-related and social exclusion factors, particularly Arab descent and speaking Arabic in the home, living in the U.S. for fewer years, and originating from Egypt, Syria, or Yemen. Arab immigrants originating from these countries were often escaping high poverty, political volatility, and war-torn areas and thus may have a greater degree of instability in the U.S. We also found that close to half of participants reported government mistrust and perceptions of being treated unfairly, and more than half reported perceived discrimination. There is pervasive documented discrimination against Arab Americans in the U.S. Negative stereotyping, hate crimes, police and law enforcement harassment, and incidents of racial discrimination against Muslims and Arabs have been well documented both in the U.S. and Europe [16-18]. Post 9/11 also resulted in Arab American immigrants accessing fewer public services, including health care, that appear to be connected to the U.S. 
Table 1 Participant characteristics and differences in social risk factors (Individual-level social determinants of health) by demographic, identity, social exclusion factors and health outcomes

Unweighted N $\quad$ Weighted percent $(95 \% \mathrm{CI}) \quad$ Social-risks (Individual-level social $\mathrm{P}$ value determinants of health)

Weighted mean

$(95 \% \mathrm{CI})$

\begin{tabular}{|c|c|c|c|c|}
\hline \multicolumn{5}{|l|}{ Demographic factors } \\
\hline Age (weighted mean $(95 \% \mathrm{CI}))$ & 411 & $38.41(35.1-41.7)$ & & \multirow[t]{5}{*}{0.36} \\
\hline $18-35$ & 195 & $44.2(36.5-51.9)$ & $2.26(2.02-2.50)$ & \\
\hline $36-45$ & 97 & $21.8(16.2-27.3)$ & $2.46(2.04-2.88)$ & \\
\hline $46-65$ & 92 & $27.1(17.6-36.6)$ & $1.95(1.54-2.36)$ & \\
\hline$>65$ & 26 & $6.8(3.0-10.5)$ & $2.42(1.77-3.07)$ & \\
\hline \multicolumn{5}{|l|}{ Gender } \\
\hline Male & 150 & $38.7(30.1-47.3)$ & $1.97(1.68-2.26)$ & \multirow[t]{2}{*}{0.01} \\
\hline Female & 269 & $61.2(52.6-69.9)$ & $2.46(2.22-2.70)$ & \\
\hline \multicolumn{5}{|l|}{ Marital status } \\
\hline Married & 220 & $51.1(43.0-59.2)$ & $2.37(2.09-2.67)$ & \multirow[t]{2}{*}{0.30} \\
\hline Not married & 192 & $48.8(40.7-56.9)$ & $2.16(1.89-2.44)$ & \\
\hline \multicolumn{5}{|l|}{ Education } \\
\hline High school or less & 135 & $28.4(22.1-34.6)$ & $2.62(2.29-2.95)$ & \multirow[t]{4}{*}{0.001} \\
\hline Some college & 99 & $25.4(17.7-33.1)$ & $2.33(2.01-2.66)$ & \\
\hline College graduate & 129 & $34.8(26.9-42.7)$ & $2.15(1.77-2.52)$ & \\
\hline Graduate school & 47 & $11.2(5.4-17.1)$ & $1.60(1.14-2.05)$ & \\
\hline \multicolumn{5}{|l|}{ Household income } \\
\hline Under $\$ 10,000$ & 63 & $14.1(9.4-18.8)$ & $2.97(2.45-3.50)$ & \multirow[t]{4}{*}{$<0.0001$} \\
\hline$\$ 10,000$ to $\$ 49,999$ & 215 & $55.8(47.5-64.1)$ & $2.53(2.29-2.76)$ & \\
\hline$\$ 50,000$ to $\$ 99,999$ & 77 & $19.1(11.9-26.3)$ & $1.58(1.17-1.99)$ & \\
\hline$\$>100,000$ & 46 & $10.8(4.8-16.8)$ & $1.54(1.19-1.88)$ & \\
\hline \multicolumn{5}{|l|}{ Identity-related factors } \\
\hline \multicolumn{5}{|l|}{ Ethnic identity } \\
\hline Arab & 283 & $90.1(87.3-92.7)$ & $2.40(2.20-2.60)$ & \multirow[t]{3}{*}{0.02} \\
\hline Chaldean & 109 & $8.6(6.2-11.1)$ & $1.86(1.50-2.23)$ & \\
\hline Neither & 10 & $1.3(0.1-2.5)$ & $1.76(0.92-2.60)$ & \\
\hline \multicolumn{5}{|l|}{ Born U.S } \\
\hline Yes & 141 & $42.3(34.1-50.5)$ & $2.04(1.72-2.37)$ & \multirow[t]{2}{*}{0.05} \\
\hline No & 276 & $57.6(49.4-65.8)$ & $2.43(2.20-2.66)$ & \\
\hline \multicolumn{5}{|l|}{ Time in U.S.for non-U.S born } \\
\hline 10 years or less & 89 & $37.4(29.2-45.5)$ & $2.80(2.38-3.21)$ & \multirow[t]{3}{*}{0.003} \\
\hline $11-20$ years & 68 & $29.3(21.8-36.8)$ & $2.77(2.24-3.29)$ & \\
\hline More than 20 years & 92 & $33.2(25.5-40.8)$ & $1.98(1.66-2.31)$ & \\
\hline \multicolumn{5}{|l|}{ Country of father origin } \\
\hline Lebanon & 163 & $33.3(28.1-38.4)$ & $2.16(1.94-2.38)$ & \multirow[t]{7}{*}{0.001} \\
\hline Iraq & 148 & $11.6(8.8-14.4)$ & $2.06(1.73-2.38)$ & \\
\hline Yemen & 63 & $35.7(29.2-42.2)$ & $2.38(2.03-2.74)$ & \\
\hline Palestine & 9 & $5(1.8-8.3)$ & $1.55(1.22-1.88)$ & \\
\hline Egypt & 13 & $7.3(3.5-11.2)$ & $3.16(2.47-3.85)$ & \\
\hline Syria & 7 & $4(1.1-6.8)$ & $3.28(1.92-4.64)$ & \\
\hline Other & 5 & $2.8(0.3-5.2)$ & $3.60(2.06-5.13)$ & \\
\hline \multicolumn{5}{|l|}{ Religion } \\
\hline Muslim & 257 & $73.9(65.5-82.2)$ & $2.39(2.19-2.58)$ & \multirow[t]{2}{*}{0.75} \\
\hline Other & 150 & $26.1(17.7-34.4)$ & $2.07(1.56-2.58)$ & \\
\hline
\end{tabular}


Table 1 (continued)

Unweighted N Weighted percent (95\% CI)

Social-risks (Individual-level social $\mathrm{P}$ value determinants of health)

Weighted mean

$(95 \% \mathrm{CI})$

Arabic spoken at home

Yes $\quad 346$

No 47

Social exclusion risk factors

Perceived discrimination

$\begin{array}{ll}\text { Yes } & 208 \\ \text { No } & 165\end{array}$

Perception of being treated unfairly

$\begin{array}{ll}\text { Agree } & 149 \\ \text { disagree } & 248\end{array}$

Deportation worry

Worried 66

Not worried

327

Government mistrust

\begin{tabular}{ll} 
Yes & 196 \\
\hline & 198
\end{tabular}

198

Health outcomes

Chronic disease

Yes 183

No

Excellent

Very good

148

Good

132

Fair

Poor

Mental health symptoms (Mean (SD)) 381 range: 1-16

$$
92.6(89.3-95.8)
$$$$
7.3(4.1-10.6)
$$

$2.45(2.25-2.65)$

0.001

$1.53(1.10-1.95)$

$2.32(2.03-2.61)$

0.58

$60(51.2-68.9)$

$2.21(1.91-2.50)$

$40(31.0-48.7)$

$36.9(29.5-44.2)$

$2.56(2.28-2.85)$

0.03

$63.1(55.7-70.4)$

2.13 (1.87-2.40)
17 (12.1-21.8)

$3.10(2.59-3.62)$

$2.23(2.04-2.42)$

49 (42.6-55.4)

$51(44.5-57.3)$

2.55 (2.29-2.80)

2.19 (1.92-2.46)

2.44 (2.09-2.79)

2.12 (1.89-2.34)

53.1 (44.9-61.2)

$2.29(1.91-2.67)$

0.01

35 (28.3-41.4)

2.04 (1.76-2.32)

$31(23.3-38.4)$

$2.28(1.87-2.69)$

$17.3(10.5-24.1)$

2.67 (1.99-3.34)

$1.8(0.29-3.4)$

4.55 (3.16-5.95)

0.002

0.06

$6.63(6.15-7.11)$

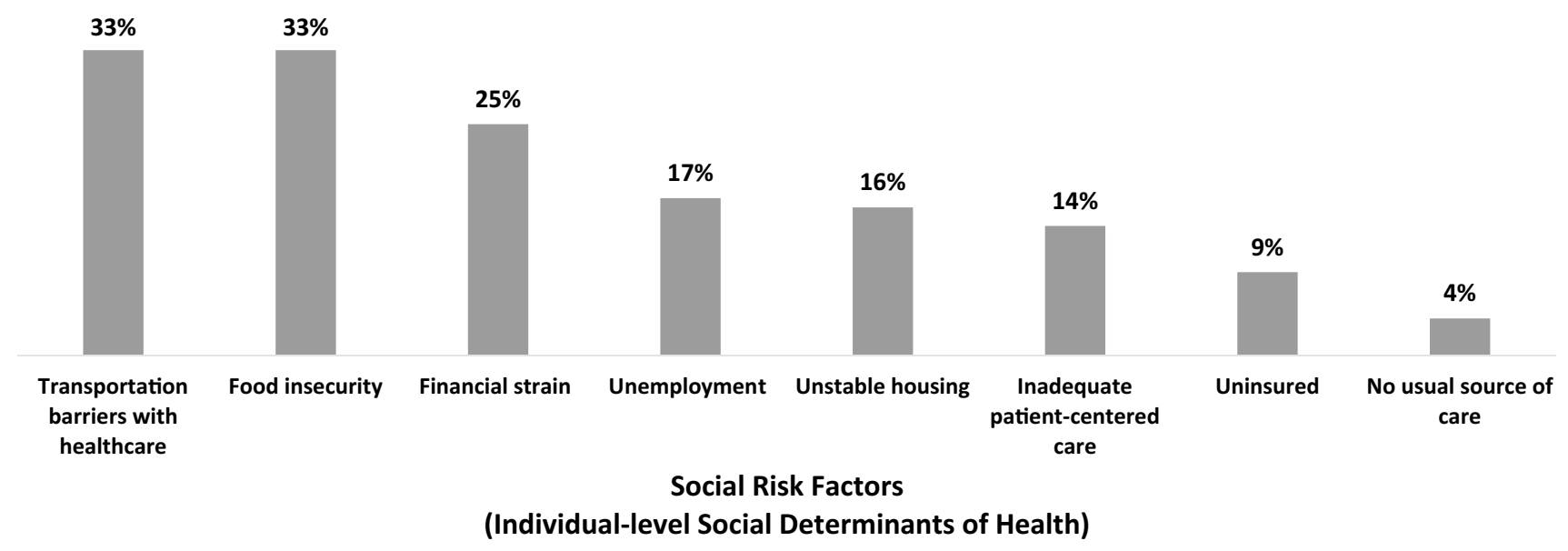

Fig. 1 Weighted prevalence of social risk factors (Individual-level social determinants of health) 
Table 2 Identity and Social exclusion factors predicting number of social risk factors (individual-level social determinants of health)

\begin{tabular}{lcc}
\hline & \multicolumn{1}{l}{$\begin{array}{l}\text { Social risk factors } \\
\text { ual-level social determinants } \\
\text { of health) }\end{array}$} \\
\cline { 2 - 3 } & Beta estimate (SE) & P value \\
\hline Perceived discrimination & $0.24(0.14)$ & 0.09 \\
Perception of being treated unfairly & $0.08(0.04)$ & 0.05 \\
Fear of deportation & $0.26(0.06)$ & $<0.001$ \\
Arab identity & $0.22(0.15)$ & 0.14 \\
Length of stay in the U.S & $-0.14(0.11)$ & 0.20 \\
Government mistrust & $0.13(0.14)$ & 0.32 \\
\hline
\end{tabular}

Multivariable linear regression models adjusted for age, gender, income, education, U.S. birth

$S E$ standard error

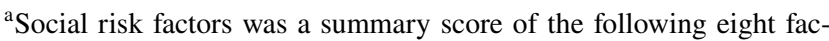
tors: transportation barriers with healthcare, food insecurity, financial strain, unemployment, unstable housing, inadequate patient-centered care, lack of insurance, and reporting no usual source of care

government [29]. More recently the Public Charge Rule, which makes it harder for certain immigrants to be granted permanent legal status in the U.S. if they have enrolled in certain assistance programs, is also further deepening fears around accessing public assistance [30]. This context also underscores our finding showing more unmet social risks associated with reports of perceptions of being treated unfairly and being worried about deportation.

In addition to discrimination, and consistent with earlier work [12], our findings also showed high rates of transportation barriers, food insecurity, financial strain, unemployment, and unstable housing on top of a greater prevalence of low-income among participants. Although some data have shown that Arab Americans have higher SES and education levels nationally, they are more impoverished and have low educational attainment in Detroit Metro area [10]. Povertyrelated factors may interact in complex ways with immigration context, experiences of discrimination, and economic context of Detroit. Other community-sampled studies have also shown high rates of mental health symptoms within
MENA population subgroups [16, 31], which coupled with negative cultural attitudes about mental health services [32], may also interact with social risks in complex ways. More qualitative and ethnographic work is needed to understand the drivers of poverty-related factors and experiences of MENA communities in the Detroit-Metro area.

There are limitations to this study that should be noted. Data were cross-sectional, therefore causality could not be discerned. Greater social risks can lead to poor health, but poor health can also lead to resource depletion and more unmet needs. Because social risk factors were not the main focus of the survey, we were limited in the domains of social risks measured. Future work with primary data collection should aim to assess all recommended domains by the National Academy of Medicine [13]. These data were collected prior to the COVID-19 pandemic, which has exacerbated individual-level social determinants of health across the nation. Therefore, the prevalence of social risks among study participants in the present may be underestimated, but nonetheless provide indicators of where social risks may be elevated in the MENA community. This was a community-based, convenience sample with a higher proportion of younger and middle-aged respondents, therefore findings may not translate to the full MENA population in the U.S. However, given that national data are sparse on the MENA community, and the sizable population in Michigan where the study took place, these findings have important implications for a large local community. Data were selfreported, which may impact the validity of key variables such as health history and immigration status. We are unable to quantify a response rate, given the public spaces where participants were recruited. Thus, we cannot determine how respondents may have differed from those who declined to participate. Finally, we did not fully measure acculturation or generational status, only where respondents were born and languages spoken in the home. These other factors may also relate to social risk factors.

Notwithstanding these limitations, our findings have important implications for clinical and public health practice. The policy climate in recent years such as attacks on the Affordable Care Act and Medicaid Expansion, and

Table 3 Number of social risk factors (individual-level social determinants of health) predicting self-related health, number of chronic conditions, and mental health symptoms

\begin{tabular}{|c|c|c|c|c|c|c|}
\hline & \multicolumn{2}{|l|}{ Self-rated health } & \multicolumn{2}{|l|}{ Chronic conditions } & \multicolumn{2}{|c|}{ Mental health symptoms } \\
\hline & Beta estimate (SE) & $\mathrm{P}$ value & Beta estimate (SE) & $\mathrm{P}$ value & Beta estimate (SE) & $\mathrm{P}$ value \\
\hline Number of social risk factors ${ }^{\mathrm{a}}$ & $0.09(0.03)$ & 0.01 & $0.11(0.03)$ & 0.004 & $0.34(0.14)$ & 0.01 \\
\hline
\end{tabular}

Multivariable linear regression models adjusted for age, gender, income, education, U.S. birth

$S E$ standard error

${ }^{a}$ Social risk factors was a summary score of the following eight factors: transportation barriers with healthcare, food insecurity, financial strain, unemployment, unstable housing, inadequate patient-centered care, lack of insurance, and reporting no usual source of care 
Public Charge Rule have created barriers for immigrant families in addressing unmet social risks. On top of this, the COVID-19 pandemic has exacerbated individual-level social determinants of health across the nation, especially with unprecedented levels of unemployment in the general population. As more healthcare delivery organizations and social service organizations aim to adopt social screening and alignment of referral strategies, especially those serving diverse immigrant communities, understanding the prevalence of social risks in their populations will help prioritize resources to those needs driving adverse health. It will also better assist local organizations serving the MENA community in adopting screening tools and co-locate resources that measure and address prevalent social exclusion factors such as discrimination. Research examining social risk factors in other MENA populations outside of Michigan, and how they relate to other health outcomes beyond those reported here is encouraged.

\section{Conclusion}

Social risk factors in MENA communities is high, especially among certain ethnic groups, and non-U.S. born individuals of low socioeconomic status. They are also high among those perceiving unequal treatment and fear deportation in the context of their community. Transportation barriers to healthcare and food insecurity are the most prevalent social risks. Those with more social risk factors report worse health. These findings have implications for developing, testing and targeting innovative social needs screening and referral models that can best serve MENA sub-populations in the U.S.

Acknowledgements This work was supported by National Cancer Institute Grant P30CA046592-29-S4.

\section{References}

1. Alderwick H, Gottlieb LM. Meanings and misunderstandings: a social determinants of health lexicon for health care systems. Milbank Q. 2019;97(2):407-19. https://doi.org/10.1111/14680009.12390 .

2. Horwitz LI, Chang C, Arcilla HN, Knickman JR. Quantifying health systems' investment in social determinants of health, by sector, 2017-19. Health Aff (Millwood). 2020;39(2):192-8.

3. Byhoff E, De Marchis EH, Gottlieb L, Halperin-Goldstein S, Nokes K, LeClair AM. Screening for immigration-related health concerns in a federally qualified health center serving a diverse Latinx community: a mixed methods study. J Immigr Minor Health. 2020;22(5):988-95.

4. Hughes AK, Woodward AT, Fritz MC, Swierenga SJ, Freddolino PP, Reeves MJ. Unmet needs of US acute stroke survivors enrolled in a transitional care intervention trial. J Stroke Cerebrovasc Dis. 2020;29(2):104462.
5. Thompson T, McQueen A, Croston M, et al. Social needs and health-related outcomes among medicaid beneficiaries. Health Educ Behav. 2019;46(3):436-44.

6. Frank J, Restar A, Kuhns L, et al. Unmet health care needs among young transgender women at risk for HIV transmission and acquisition in two urban US cities: the lifeskills study. Transgend Health. 2019;4(1):1-8.

7. Dallo FJ, Ruterbusch JJ, Kirma JD, Schwartz K, Fakhouri M. A Health profile of Arab Americans in Michigan: a novel approach to using a hospital administrative database. J Immigr Minor Health. 2016;18(6):1449-54.

8. Arab American Institute. Ensuring a Fair and Accurate Count in the 2020 Census: Promoting Representation of our Communities. Washington D.C. 2019.

9. Bureau UC. People Reporting Ancestry: 2017 American Community Survey 1-Year Estimates. In: U.S. Census Bureau. 2018.

10. Arab American Institute Foundation. Arab American demographics/quick facts about Arab Americans. 2018. https://www. aaiusa.org/demographics. Accessed 12 Dec 2019.

11. Nassar-McMillan SC, Julie Hakim-Larson KJA. Biopsychosocial perspectives on Arab Americans: culture, development, and health. New York: Springer; 2014.

12. Neumayer HWS, Fussman C, McKane P. Health risk behaviors among Arab Adults within the State of Michigan: 2016 Arab behavioral risk factor survey. Lansing, MI: Michigan Department of Health and Human Services, lifecourse epidemiology and genomics division and health disparities reduction and minority health section. 2017.

13. Institute of Medicine. Capturing social and behavioral domains and measures in electronic health records: phase 2. Washington: The National Academies Press; 2014.

14. U.S. Department of Health and Human Services (HHS). Healthy People 2020: An opportunity to address the societal determinants of health in the United States. 2017. https://www.healt hypeople.gov/sites/default/files/SocietalDeterminantsHealth.pdf

15. Assari S, Lankarani MM. Discrimination and psychological distress: gender differences among Arab Americans. Front Psychiatry. 2017;8:23.

16. Kader F, Bazzi L, Khoja L, Hassan F, de Leon CM. Perceived discrimination and mental well-being in Arab Americans from Southeast Michigan: a cross-sectional study. J Racial Ethn Health Disparities. 2019. https://doi.org/10.1007/s40615-01900672-y.

17. Abuelezam NN, El-Sayed AM, Galea S. Arab American health in a racially charged US. Am J Prev Med. 2017;52(6):810-2.

18. Kulwicki A, Khalifa R, Moore G. The effects of September 11 on Arab American nurses in metropolitan Detroit. J Transcult Nurs. 2008;19(2):134-9.

19. Davis BA. Discrimination: a social deterimant of health inequities. Health Affairs Blog. 2020. https://www.healthaffairs.org/ do/10.1377/hblog20200220.518458/full/. Accessed 25 Feb 2020.

20. Eismann EA, Theuerling J, Maguire S, Hente EA, Shapiro RA. Integration of the safe environment for every kid (SEEK) model across primary care settings. Clin Pediatr (Phila). 2019;58(2):166-76.

21. The 2016 Annual Homeless Assessment Report (AHAR) to congress. Washington, DC, US department of housing and urban development. 2016.

22. National Cancer Institute. Health information national trends survey. 2019. https://hints.cancer.gov/.

23. Williams DR, Yan Yu, Jackson JS, Anderson NB. Racial differences in physical and mental health: socio-economic status stress and discrimination. J Health Psychol. 1997;2(3):335-51.

24. De Vogli R, Brunner E, Marmot MG. Unfairness and the social gradient of metabolic syndrome in the Whitehall II Study. J Psychosom Res. 2007;63(4):413-9. 
25. De Vogli R, Ferrie JE, Chandola T, Kivimäki M, Marmot MG. Unfairness and health: evidence from the Whitehall II study. J Epidemiol Community Health. 2007;61(6):513-8.

26. Kroenke K, Spitzer RL, Williams JB, Lowe B. An ultra-brief screening scale for anxiety and depression: the PHQ-4. Psychosomatics. 2009;50(6):613-21.

27. Fleming PJ, Novak NL, Lopez WD. U. S. Immigration Law enforcement practices and health inequities. Am J Prev Med. 2019;57(6):858-61.

28. Fleming PJ, Lopez WD, Mesa $\mathrm{H}$, et al. A qualitative study on the impact of the 2016 US election on the health of immigrant families in Southeast Michigan. BMC Public Health. 2019;19(1):947.

29. Inhorn MC, Serour GI. Islam, medicine, and Arab-Muslim refugee health in America after 9/11. Lancet. 2011;378(9794):935-43.

30. Perreira KM, Yoshikawa H, Oberlander J. A new threat to immigrants' health-The public-charge rule. N Engl J Med. 2018;379(10):901-3.
31. Abuelezam NN, El-Sayed AM. Objective and subjective poor mental health indicators among Arab Americans in Michigan: a population-based study. Ethn Health. 2018;225:1-10.

32. Abuelezam NN, El-Sayed AM, Galea S. The health of Arab Americans in the United States: an updated comprehensive literature review. Front Public Health. 2018;6:262.

Publisher's Note Springer Nature remains neutral with regard to jurisdictional claims in published maps and institutional affiliations. 